\title{
Médiévales
}

Langues, Textes, Histoire

56 | printemps 2009

Pratiques de l'écrit

\section{Martin NEJEDLÝ, Středověký mýtus o Meluzíně a rodová pověst Lucemburků, Prague, Scriptorium, 2007, $503 \mathrm{p}$.}

Olivier Marin

\section{CpenEdition}

\section{Journals}

Édition électronique

URL : https://journals.openedition.org/medievales/5615

DOI : 10.4000/medievales.5615

ISSN : 1777-5892

Éditeur

Presses universitaires de Vincennes

Édition imprimée

Date de publication : 30 juin 2009

Pagination : 184-186

ISBN : 978-2-84292-232-0

ISSN : 0751-2708

Référence électronique

Olivier Marin, « Martin NEJEdLy, Středověký mýtus o Meluzíně a rodová pověst Lucemburků, Prague, Scriptorium, 2007, 503 p. », Médiévales [En ligne], 56 | printemps 2009, mis en ligne le 21 septembre 2009, consulté le 24 avril 2022. URL : http://journals.openedition.org/medievales/5615 ; DOI : https:// doi.org/10.4000/medievales.5615

Ce document a été généré automatiquement le 24 avril 2022.

Tous droits réservés 


\title{
Martin NEJEDLÝ, Středověký mýtus o Meluzíně a rodová pověst Lucemburki̊, Prague, Scriptorium, 2007, 503 p.
}

\author{
Olivier Marin
}

1 Pour embrasser dans la diversité de ses expressions le mythe de Mélusine il faut une intelligence et une culture historiques à la mesure du continent européen. Martin Nejedlý est l'un des très rares médiévistes actuels à pouvoir prétendre manier un compas aussi large. Ancien élève de Jacques Le Goff sous la direction duquel il a soutenu une thèse remarquée sur l'imaginaire politique de Froissart (La représentation des pouvoirs et des hiérarchies dans les chroniques de Jean Froissart, Villeneuve d'Ascq, 1999), il se distingue des autres historiens tchèques par sa pratique de l'anthropologie en même temps que par l'intérêt constant qu'il porte aux sources littéraires, spécialement celles écrites en moyen français. Sans doute cette double disposition l'a-t-elle convaincu de s'intéresser à la fée "maternelle et défricheuse » sur laquelle J. Le Goff et E. Le Roy Ladurie s'étaient naguère penchés dans un article retentissant des Annales. Il publie ici le fruit de son enquête sous la forme d'un travail d'habilitation présenté récemment à l'université Charles de Prague et intitulé Le mythe médiéval de Mélusine et la légende généalogique des Luxembourg.

2 L'ouvrage se recommande d'abord par la quantité des matériaux primaires et secondaires collectés. Martin Nejedlý ne s'est pas contenté de prendre appui sur les deux textes phares de la légende, le roman de Jean d'Arras (1393) et sa mise en octosyllabes par Coudrette quelques années plus tard. Il remonte jusqu'à leurs antécédents du XII ${ }^{e}$ siècle, démêle les variantes de la tradition et en dépiste, autant que faire se peut, les sources. Plus encore, il adjoint aux textes une moisson d'images en tout genre, enluminures bien sûr, mais aussi armoiries, faïences ou sculptures. Le lecteur sait gré à la maison d'édition de ne pas avoir lésiné sur les moyens pour illustrer au mieux le propos de l'auteur : sont insérées près de 260 reproductions, dont beaucoup en couleur. On conçoit ensuite qu'assimiler la bibliographie sur le sujet représente un véritable tour de force, tant celle-ci est surabondante et éclatée entre des spécialités 
étrangères les unes aux autres. Ce faisant, Martin Nejedlý fournit au lecteur une somme précieuse, exhaustive et à jour, des connaissances. Encore l'érudition mise en œuvre est-elle toujours dominée, grâce à un style étincelant qui sait rendre à Mélusine sa grâce native. Cela faisait assurément longtemps qu'il ne nous avait pas été donné d'ouvrir un livre d'histoire réconciliant avec un tel bonheur les exigences académiques et la puissance poétique de suggestion.

3 La deuxième grande qualité de l'ouvrage est d'éclairer un pan largement méconnu, celui de la réception du mythe de Mélusine dans les pays tchèques. Comme on pouvait s'y attendre, c'est l'avènement des Luxembourg sur le trône de Bohême qui introduisit là-bas le thème mélusinien, dont l'auteur recueille des traces ténues dans l'héraldique du temps. Le mythe connut un second départ à l'aube de l'époque moderne, la traduction allemande de Coudrette par Thüring de Ringoltingen (1456) accédant précocement et généreusement aux honneurs de l'impression, avant d'être à son tour adaptée en tchèque en 1595 sous le titre Kronika kratochvilná o ctné a šlechetné panně Meluzíně. Lue et relue, l'histoire de Mélusine passa alors dans le folklore et se naturalisa, en un bel exemple d'aller-retour entre les cultures savante et livresque d'une part, populaire et orale de l'autre. Malgré qu'elles en eussent, les Lumières si hostiles à l'irrationnel moyenâgeux ne purent avoir raison de la fée. A l'époque romantique, celleci inspira encore et toujours poètes (F.L. Čelakovský) et compositeurs (Z. Fibich), au point d'être désormais intégrée au panthéon des divinités slaves. On pourra regretter que Martin Nejedlý ne se risque pas à suivre les ultimes avatars du mythe mélusinien au $\mathrm{XX}^{\mathrm{e}}$ siècle. Mais il vrai que l'entreprise risquait de donner une ampleur démesurée à une œuvre déjà fort volumineuse.

Si le livre a toutes les chances de faire date dans l'historiographie, c'est enfin pour une autre raison plus décisive encore. La fine pointe de l'argumentation consiste en effet à montrer que la Bohême, loin de n'en avoir été qu'un réceptacle passif, influa sur la construction même du mythe mélusinien. Le roman de Mélusine ne fut-il pas dédié par Jean d'Arras au margrave de Moravie Josse (1354-1411), le cousin de Jean de Berry? N'est-il pas moins remarquable que le texte fasse une large place aux deux fils de Mélusine, Antoine et Renaud, qui deviendront respectivement comte de Luxembourg et roi de Bohême? Ce tropisme tchèque avait certes été relevé depuis Louis Stouff. Mais il revient à Martin Nejedlý d'en éclairer les attendus. Attendus culturels : c'est l'occasion pour l'auteur d'explorer en détail l'importance de l'itinéraire Paris-Prague pour tant d'artistes et poètes de ce temps, à commencer par Jean Froissart, mais aussi pour un Guillaume de Machaut ou un Eustache Deschamps; intensifiée par la fameuse visite de Charles IV à Paris en 1378 à laquelle F. Šmahel vient de consacrer une autre étude magistrale (Cesta Karla IV. do Francie. 1377-1378, Prague, 2006), une telle familiarité entre les élites intellectuelles des deux pays ne se retrouvera pas avant la Première République tchécoslovaque. Attendus politiques: dans le sillage de L. Harf-Lancner, Martin Nejedlý restitue les raisons diverses qu'avaient les Valois, les Lusignan et les Luxembourg de conforter leurs alliances matrimoniales par un mythe fondateur commun. Cela nous vaut une interprétation renouvelée de la conjoncture des années 1390 sur fond de crise de légitimité dynastique et de rêves de croisade. Les pages superbes qui lui sont dévolues achèvent de faire de cette fable sur le pouvoir, l'amour et le malheur un grand livre, dont on ne peut que souhaiter la traduction rapide en français. 